\title{
Dopamine D2 Receptor-Mediated Regulation of Partner Preferences in Female Prairie Voles (Microtus ochrogaster): A Mechanism for Pair Bonding?
}

\author{
Zuoxin Wang, Guozhong Yu, Carissa Cascio, Yan Liu, Brenden Gingrich, and Thomas R. Insel \\ Emory University
}

\begin{abstract}
This study examined the role of dopamine (DA) in partner preference (PP) formation in female prairie voles (Microtus ochrogaster). The nonspecific DA antagonist haloperidol blocked mating-induced PP, whereas the nonspecific DA agonist apomorphine induced PP without mating. The D2 antagonist eticlopride, but not the D1 antagonist SCH23390, blocked PP, whereas the D2 agonist quinpirole, but not the D1 agonist SKF38393, induced PP without mating. Injections of eticlopride before or immediately after mating, but not $24 \mathrm{hr}$ after mating, impaired PP, indicating that DA's effects were not due to an interference with mating or sensory recognition. Finally, intracerebroventricular injections of eticlopride diminished PP. Together, these data suggest that mating-induced PP requires activation of D2 receptors and that social experience may activate dopaminergic pathways, with enduring effects on behavior.
\end{abstract}

Recent studies have begun to explore the neural mechanisms underlying complex social behaviors such as pair bonding (Young, Wang, \& Insel, 1997). Pair bonds are long-term, selective social attachments that are characteristic of social organization in human and other primate societies. Pair bonds can also be studied in monogamous, nonprimate species. Monogamous mammals, by definition, form long-term, selective attachments. Several recent studies have demonstrated that pair bond formation can be operationally defined and rigorously measured in the laboratory. One of the earliest and most important measures of the pair bond is the formation of a partner preference, a simple test of whether the individual chooses to affiliate with a partner more than a stranger (Carter \& Getz, 1993). In a laboratory setting, partner preference formation can serve as a quantifiable indication of pair bonding (Insel, Preston, \& Winslow, 1995).

The prairie vole (Microtus ochrogaster) is a monogamous

Zuoxin Wang and Brenden Gingrich, Department of Psychiatry and Behavioral Sciences and Graduate Program in Neuroscience, Emory University; Guozhong Yu and Yan Liu, Department of Psychiatry and Behavioral Sciences, Emory University; Carissa Cascio, Graduate Program in Neuroscience, Emory University; Thomas R. Insel, Department of Psychiatry and Behavioral Sciences, Graduate Program in Neuroscience, and Yerkes Regional Primate Research Center, Emory University.

We thank Larry Young, James Winslow, and Matthew Smith for their critical reading of the manuscript. We also thank Clinton Kilts for generously providing us with the dopaminergic compounds. This research was supported by National Institute of Mental Health Grants 54554 and 56539 and by the Whitehall Foundation.

Correspondence concerning this article should be addressed to Zuoxin Wang, who is now at the Department of Psychology, Florida State University, 209 Copeland Avenue, Tallahassee, Florida 32306-1270. Electronic mail may be sent to zwang@ psy.fsu.edu. rodent that in the field forms long-term bonds (Getz, Carter, \& Gavish, 1981; Getz \& Hofmann, 1986) and in the laboratory mates preferentially with one partner (Dewsbury, 1987). After mating, males and females share a nest, remain together during gestation, and exhibit biparental care throughout lactation (McGuire \& Novak, 1984; Oliveras \& Novak, 1986). Mating also induces a partner preference in both male and female prairie voles. The development of a partner preference is dependent upon mating because exposure to a conspecific without mating fails to induce this behavior (Insel et al., 1995; Williams, Catania, \& Carter, 1992; Winslow, Hastings, Carter, Harbaugh, \& Insel, 1993). In female prairie voles, long-time cohabitation with a male also induces a partner preference (Williams, Catania, \& Carter, 1992). Mating-induced partner preference appears to be associated with pair bonding in prairie voles, as mating does not induce a partner preference in the closely related, promiscuous montane vole (M. montanus; Dewsbury, 1987; Insel et al., 1995; Shapiro \& Dewsbury, 1990).

The neural mechanisms underlying partner preference formation may include, but are not limited to, reward, memory formation, and sensory processing (Insel \& Hulihan, 1995). Because dopamine has been implicated in each of these mechanisms (Blackburn, Pfaus, \& Phillips, 1992; Bozarth, 1991; Wise \& Rompre, 1989), we hypothesized that mating-induced partner preferences in prairie voles may be mediated by a dopaminergic process.

The present study was undertaken to examine the involvement of dopamine in the regulation of partner preferences in female prairie voles. We hypothesized that in voles, as in other rodents (Meisel, Camp, \& Robinson, 1993; Pfaus, Damsma, Wenkstern, \& Fibiger, 1995), mating induces dopamine release, which in turn acts on a specific, receptormediated mechanism to regulate partner preferences. This hypothesis was tested in a series of experiments with dopaminergic drugs. In the first experiment, we examined 
the effects of a nonspecific agonist and a nonspecific antagonist on partner preferences. In the second experiment, we compared the effects of D1 and D2 receptor-specific compounds. In the third experiment, we investigated whether dopamine influences the formation or expression of a partner preference. In the fourth experiment, we tested whether dopamine acts on memory consolidation to influence partner preferences. Finally, we examined the effects of a dopamine D2 antagonist in the central nervous system on partner preference behavior. Together, these results suggest that dopamine is involved in the regulation of partner preference through a $\mathrm{D} 2$ receptor-mediated mechanism.

\section{Method}

\section{Subjects}

Subjects were sexually naive female prairie voles (Microtus ochrogaster) that were from the F2 generation of a laboratory breeding colony started with field-captured animals. After weaning (21 days old), subjects were housed in same-sex sibling pairs in plastic cages $(20 \times 25 \times 40 \mathrm{~cm})$ that contained cedar chip bedding. Water and food were provided ad libitum. All subjects were maintained on a 14:10-hr light-dark cycle with lights on at 0700 . The temperature was about $20^{\circ} \mathrm{C}$. Subjects were housed until they were 70-90 days old before being assigned to each experiment.

\section{Experimental Procedure}

Dopamine regulation of partner preferences was examined in five experiments, all of which were based on the observation that female prairie voles that were mated for $24 \mathrm{hr}$ consistently form a preference for their mate, whereas females that cohabited with a male for $6 \mathrm{hr}$ without mating do not exhibit a preference (Insel \& Hulihan, 1995; Williams, Insel, Harbaugh, \& Carter, 1994). Experiment 1 was designed to test whether the nonspecific dopamine agonist apomorphine induced a partner preference in the absence of mating or whether the nonspecific dopamine receptor antagonist haloperidol blocked a mating-induced partner preference. In Experiment 1A, sexually naive females were divided into four groups that received an intraperitoneal injection of either saline $(n=10)$ or $4 \mu \mathrm{g}(n=9), 50 \mu \mathrm{g}(n=10)$, or $100 \mu \mathrm{g}(n=10)$ apomorphine (in $200 \mu \mathrm{l}$ saline per $40 \mathrm{~g}$ body weight), respectively. Immediately after the injection, subjects were paired with a sexually naive male for $6 \mathrm{hr}$ while their behavior was videotaped to verify the absence of mating. After $6 \mathrm{hr}$, the male partner was removed and the female subjects were placed in a three-chamber apparatus for a partner preference test (see below). In Experiment $1 \mathrm{~B}$, females were injected subcutaneously with $0.5 \mu \mathrm{g}$ estradiol benzoate (EB) for 3 days, which successfully brought them into estrus. Sexually receptive females were then divided into three groups that received an injection of either saline $(n=6)$ or $0.4 \mu \mathrm{g}$ $(n=6)$ or $4 \mu \mathrm{g}(n=8)$ haloperidol (in $200 \mu \mathrm{l}$ saline) and were then paired with a sexually experienced male for $24 \mathrm{hr}$. The behavior was videotaped to verify mating and to investigate haloperidol's effects on sociosexual behavior. Thereafter, the male was removed and the female subjects were tested for partner preferences.

In Experiment 2, receptor-specific antagonists and agonists were used to define the receptor-mediated mechanism involved in dopamine regulation of partner preferences. In Experiment $2 \mathrm{~A}$, female prairie voles were first injected with $\mathrm{EB}(0.5 \mu \mathrm{g})$ for 3 days to bring them into estrus. They were then divided into three groups that received an injection of either saline $(n=10), 50 \mu \mathrm{g}$ of the dopamine D1 receptor antagonist $\mathrm{SCH} 23390(n=10)$, or $50 \mu \mathrm{g}$ of the $\mathrm{D} 2$ receptor antagonist eticlopride $(n=9)$. Subjects were then paired with a sexually experienced male for $24 \mathrm{hr}$ while the behavior was videotaped to verify mating. After $24 \mathrm{hr}$ of mating, the males were removed and females were tested for partner preferences. In Experiment $2 \mathrm{~B}$, sexually naive females were divided into two groups ( $n=10$ per group) that were injected with $50 \mu \mathrm{g}$ of either the D1 receptor agonist SKF38393 or the D2 receptor agonist quinpirole. After being housed with a sexually naive male for $6 \mathrm{hr}$ without mating (confirmed by videotaped behavior), subjects were tested for partner preferences. The $50-\mu \mathrm{g}$ doses $(1.25 \mathrm{mg} / \mathrm{kg}$ body weight) of the D1 or D2 agonist or antagonist were chosen on the basis of previous studies examining dopamine effects on sexual behavior or on memory consolidation in rats or mice (Castellano, Cestari, Cabib, \& Puglisi-Allegra, 1991; Castellano, Cestari, Cabib, \& Puglisi-Allegra, 1994; Melis \& Argiolas, 1995).

Experiment 3 extended Experiments 1 and 2 to examine whether the D2 receptor antagonist affected the formation or expression (or both) of partner preferences. Females brought into estrus by EB injections were divided into three groups. In Group 1 (control, $n=7$ ), females were injected with saline, mated with a sexually experienced male for $24 \mathrm{hr}$, and again injected with saline. In Group $2(n=9)$, females were injected with eticlopride $(50 \mu \mathrm{g}$ in $200 \mu \mathrm{l}$ saline), mated for $24 \mathrm{hr}$, and then injected with saline. In Group $3(n=9)$, females were injected with saline, mated for 24 $\mathrm{hr}$, and then injected with eticlopride $(50 \mu \mathrm{g})$. Behavioral interaction between the female and the male partner during the 24-hr period was videotaped to verify mating. After the second injection, females were tested for partner preferences.

Because treatment with the D2 antagonist immediately after mating in Experiment 3 might influence both the consolidation of the social memory as well as sensory discrimination during the subsequent partner preference test, Experiment 4 was performed to test whether the D2 antagonist might influence partner preferences $24 \mathrm{hr}$ after mating (presumably after memory consolidation). After $24 \mathrm{hr}$ of mating, the females and the male partner were separated for $24 \mathrm{hr}$. Thereafter, subjects were divided into two groups that received an injection of either saline $(n=8)$ or the D2 antagonist eticlopride $(50 \mu \mathrm{g}$ in $200 \mu \mathrm{l}$ saline; $n=8)$, followed by a partner preference test.

Experiment 5 was designed to test the hypothesis that dopamine acts in the central nervous system to regulate partner preference formation. Females were stereotaxically implanted with a 26-gauge guide cannula (Plastics One, Roanoke, VA) aimed to the lateral ventricle (Wang, Ferris, \& De Vries, 1994; Winslow et al., 1993). After 3 days of recovery, females received a microinjection of either artificial cerebrospinal fluid (CSF: $200 \mathrm{nl}$; BioFluid, Rockville, $\mathrm{MD} ; n=7)$ or $200 \mathrm{ng}$ of eticlopride in CSF $(n=6)$, were mated with a male for $24 \mathrm{hrs}$, and were then tested for partner preferences. Microinjections were made with a 33-gauge needle that extended $1 \mathrm{~mm}$ below the guide cannula into the lateral ventricle. The needle was connected to a Hamilton syringe through PE-20 tubing. Plunger depression was done slowly, requiring about $10 \mathrm{~s}$ per injection. After behavioral testing, subjects received an injection of $2 \%$ india ink ( $200 \mathrm{nl}$ ), and staining of the ventricular system was checked to verify cannula placement.

All dopaminergic compounds were purchased from Research Biochemical (Natick, MA) and dissolved in saline $(0.9 \% \mathrm{NaCl}$, VWR Scientific Products, Pittsburgh, PA) before each experiment.

\section{Partner Preference Test}

Partner preference was tested in a three-chamber apparatus as described previously (Williams, Catania, \& Carter, 1992; Winslow 
et al., 1993). Briefiy, the testing apparatus consisted of a central cage $(20 \times 25 \times 45 \mathrm{~cm})$ joined by hollow tubes $(7.5 \times 16 \mathrm{~cm})$ to two parallel, identical cages, each housing a stimulus animal. The female subjects were free to move throughout the apparatus, and stimulus animals were loosely tethered within their separate cages and had no direct contact with each other. The familiar partner (the male that cohabited or was mated with the subject) and a stranger (a male that had not previously encountered the subject) were used as stimulus animals. The subjects were put into the central cage, and their behavior was recorded for $3 \mathrm{hr}$ with a time-lapse video recording system.

\section{Data Acquisition and Analysis}

For the partner preference test, the following behavioral measures were recorded on a computerized event-recording system (The Observer 2.0, Noldus Information Technology, Wageningen, The Netherlands): (a) duration and frequency of the subject's side-by-side contact with either the partner or the stranger, (b) time that subjects spent in each cage, and (c) frequency of cage entry. Differences in side-by-side contact with the partner or the stranger within each treatment group were analyzed with a Mann-Whitney nonparametric test (because of nonhomogeneity of variance). Treatment effects on the time that subjects spent in each cage within each experiment were analyzed with a Kruskal-Wallis nonparametric test. Because dopamine's effects on partner preferences could be secondary to its effects on locomotor activity during a preference test, the frequency of the subject's entries into the partner's or stranger's cage was recorded and subsequently used as an index of locomotor activity. Treatment effects were analyzed with a one-way analysis of variance (ANOVA) followed by a Student Newman-Keuls (SNK) post hoc test.

Differences in partner preferences could also be due to treatment effects on mating or other aspects of social interaction between the subject and the male partner in the initial 6-hr or 24-hr exposure. Therefore, duration and frequency of mating and side-by-side contact between the two were quantified throughout the 6-hr cohabitation, or the first $6 \mathrm{hr}$ for mating groups. These data were analyzed by a one-way ANOVA followed by an SNK test.

\section{Results}

\section{Apomorphine-Induced Partner Preferences in the Absence of Mating}

As expected from previous studies (Insel \& Hulihan, 1995; Williams et al., 1994), 6 hr of cohabitation with a male without mating did not induce a partner preference in female prairie voles. Control females (injected with saline) spent roughly equal time in side-by-side contact with the partner or a stranger (see Figure 1a). Females treated with either 4 $\mu \mathrm{g}(Z=3.31, p<.01), 50 \mu \mathrm{g}(Z=3.78, p<.001)$, or 100 $\mu \mathrm{g}(Z=1.97, p<.05)$ apomorphine spent more time in contact with the partner than with a stranger (Figure 1a). These females also tended to spend more time in the partner's cage than did females injected with saline (see Table 1). Females injected with $50 \mu \mathrm{g}$ apomorphine contacted the partner more, whereas females injected with $4 \mu \mathrm{g}$ or $50 \mu \mathrm{g}$ apomorphine contacted a stranger less than did females injected with saline. No treatment effects were detected in locomotor activity during the partner preference test. During the initial 6-hr cohabitation with the male, none of the females showed lordosis. However, relative to salineinjected females, females injected with $50 \mu \mathrm{g}$ apomorphine spent less time in contact with the male.

\section{Haloperidol Diminished Mating-Induced Partner Preferences}

As in previous studies (Insel et al., 1995), 24 hr of mating induced partner preferences in female prairie voles. Females
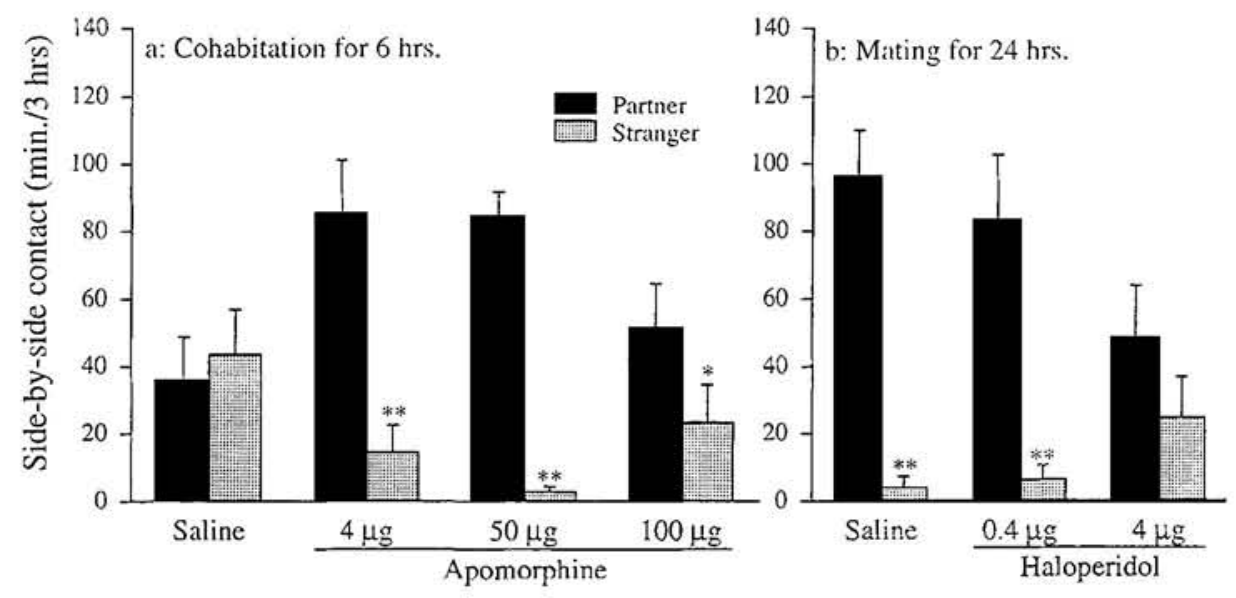

Figure 1. Effects of the dopamine agonist apomorphine and the dopamine antagonist haloperidol on partner preferences in female prairie voles. (a) After cohabitation with a male for $6 \mathrm{hr}$ without mating, control (saline-injected) females had similar side-by-side contact with either the partner or a stranger in a 3-hr test. However, females injected with apomorphine before cohabitation spent more time with the partner than with a stranger. (b) Females mated for $24 \mathrm{hr}$ had more contact with the partner than with a stranger, as did females injected with $0.4 \mu \mathrm{g}$ haloperidol before mating. Females injected with $4.0 \mu \mathrm{g}$ haloperidol before mating did not differ in contact with either male. $* p<.05$ and $* * p<.01$, Mann-Whitney nonparametric test. Error bars indicate standard errors of the means. 
Table 1

Effects of Apomorphine on Social Behaviors During Cohabitation and Partner Preference Tests

\begin{tabular}{|c|c|c|c|c|c|}
\hline \multirow[b]{2}{*}{ Behavior } & \multirow[b]{2}{*}{ Measurement } & \multirow[b]{2}{*}{ Saline } & \multicolumn{3}{|c|}{ Apomorphine } \\
\hline & & & $4 \mu \mathrm{g}$ & $50 \mu \mathrm{g}$ & $100 \mu \mathrm{g}$ \\
\hline \multicolumn{6}{|c|}{ During partner preference test } \\
\hline In partner's cage (min) & dur. & $66.2 \pm 16.6$ & $106.3 \pm 14.8$ & $121.0 \pm 8.6$ & $90.3 \pm 11.8$ \\
\hline In stranger's cage (min) & dur. & $71.8 \pm 15.3$ & $31.3 \pm 11.3$ & $19.4 \pm 4.1$ & $46.4 \pm 13.1$ \\
\hline Contact with the partner & freq. & $13.2 \pm 3.6_{\mathrm{a}}$ & $14.8 \pm 2.1_{a}$ & $24.2 \pm 3.0_{b}$ & $14.6 \pm 2.6_{a}$ \\
\hline Contact with a stranger & freq. & $10.9 \pm 2.8_{a}$ & $4.0 \pm 1.8 \mathrm{~b}$ & $3.6 \pm 1.4_{b}$ & $5.6 \pm 1.5_{\mathrm{a}, \mathrm{b}}$ \\
\hline Partner's cage entry & freq. & $40.6 \pm 4.3$ & $35.4 \pm 5.9$ & $41.5 \pm 6.5$ & $46.9 \pm 5.4$ \\
\hline Stranger's cage entry & freq. & $40.2 \pm 3.6$ & $36.6 \pm 8.8$ & $25.8 \pm 4.8$ & $34.9 \pm 6.8$ \\
\hline \multicolumn{6}{|c|}{ During cohabitation with a male } \\
\hline $\begin{array}{l}\text { Side-by-side contact (min) } \\
\text { Mating }\end{array}$ & $\begin{array}{l}\text { dur. } \\
\text { freq. }\end{array}$ & $244.5 \pm 11.1_{a}$ & $217.7 \pm \frac{14.1_{\mathrm{a}, \mathrm{b}}}{0}$ & $\begin{array}{c}196.6 \pm 9.6 \mathrm{~b} \\
0\end{array}$ & $241.6 \pm \frac{14.5_{\mathrm{a}, \mathrm{b}}}{0}$ \\
\hline
\end{tabular}

Note. The data represent mean \pm standard error of the mean. The subscript letters indicate group differences at the level of $p<.05$, based on a post hoc test following a Kruskal-Wallis nonparametric test (for durations) or analysis of variance (for frequencies). dur. $=$ duration; freq. $=$ frequency.

injected with saline and mated for $24 \mathrm{hr}$ spent more time side-by-side with the partner than with a stranger $(Z=2.88$, $p<.01$; see Figure $1 \mathrm{~b}$ ). The partner preference was also observed in females injected with low-dose haloperidol $(0.4$ $\mu \mathrm{g} ; Z=2.24, p<.05$ ) but not in females injected with high-dose haloperidol ( $4 \mu \mathrm{g}$; see Figure 1b). Females injected with high-dose haloperidol also spent less time in the partner's cage relative to saline-injected females and had more contact with a stranger in comparison with the other two experimental groups (see Table 2). No treatment effects were found in locomotor activity during the preference test or in mating and social contact during the first $6 \mathrm{hr}$ of mating.

\section{D2, but Not D1, Receptor Antagonist Blocked Partner Preferences}

The dopamine receptor antagonist blocked matinginduced partner preferences in a receptor-specific manner.
Females that were injected with the D1 receptor antagonist $\mathrm{SCH} 23390$ and mated for $24 \mathrm{hr}$ had more side-by-side contact with the partner than with a stranger $(Z=3.02$, $p<.01)$, as did the females injected with saline $(Z=3.70$, $p<.001$; see Figure 2a). However, females injected with the D2 receptor antagonist eticlopride showed similar amounts of contact with the partner and a stranger (Figure 2a). Eticlopride-treated females spent less time in the partner's cage than did females injected with either SCH23390 or saline ( $H=6.48, p<.05$; see Figure $2 b)$. No treatment effects were detected in locomotor activity during the preference test or in sociosexual behaviors during the first $6 \mathrm{hr}$ of the mating period.

\section{D2 Receptor Agonist Induced Partner Preferences}

In the absence of mating experience, females injected with the D2 receptor agonist quinpirole appeared to develop a partner preference, as they subsequently showed more

Table 2

Effects of Haloperidol on Social Behaviors During Mating and During a Partner Preference Test

\begin{tabular}{lcccc}
\hline & & & \multicolumn{2}{c}{ Haloperidol } \\
\cline { 3 - 5 } \multicolumn{1}{c}{ Behavior } & Measurement & Saline & $0.4 \mu \mathrm{g}$ & $4.0 \mu \mathrm{g}$ \\
\hline & \multicolumn{2}{c}{ During partner preference test } \\
In partner's cage (min) & dur. & $140.2 \pm 8.8_{\mathrm{a}}$ & $102.4 \pm 22.3_{\mathrm{a}, \mathrm{b}}$ & $79.8 \pm 15.7_{\mathrm{b}}$ \\
In stranger's cage (min) & dur. & $17.5 \pm 5.5$ & $53.1 \pm 20.4$ & $56.0 \pm 16.2$ \\
Contact with the partner & freq. & $27.0 \pm 5.0$ & $19.3 \pm 4.6$ & $18.9 \pm 3.5$ \\
Contact with a stranger & freq. & $3.2 \pm 1.3 \mathrm{a}$ & $6.2 \pm 2.1_{\mathrm{a}}$ & $15.9 \pm 4.3_{\mathrm{b}}$ \\
Partner's cage entry & freq. & $34.7 \pm 10.1$ & $34.7 \pm 7.4$ & $48.3 \pm 9.7$ \\
Stranger's cage entry & freq. & $21.8 \pm 4.5$ & $38.2 \pm 7.5$ & $48.8 \pm 10.4$ \\
\hline & & During mating & & \\
Side-by-side contact (min) & dur. & $229.5 \pm 11.6$ & $218.8 \pm 21.7$ & $211.9 \pm 38.0$ \\
Mating & freq. & $31.3 \pm 4.8$ & $28.7 \pm 6.0$ & $29.5 \pm 7.5$ \\
\hline
\end{tabular}

Note. The data represent mean \pm standard error of the mean. The subscript letters indicate group differences at the level of $p<.05$, based on a post hoc test following a Kruskal-Wallis nonparametric test (for durations) or analysis of variance (for frequencies). dur. = duration; freq. = frequency. 

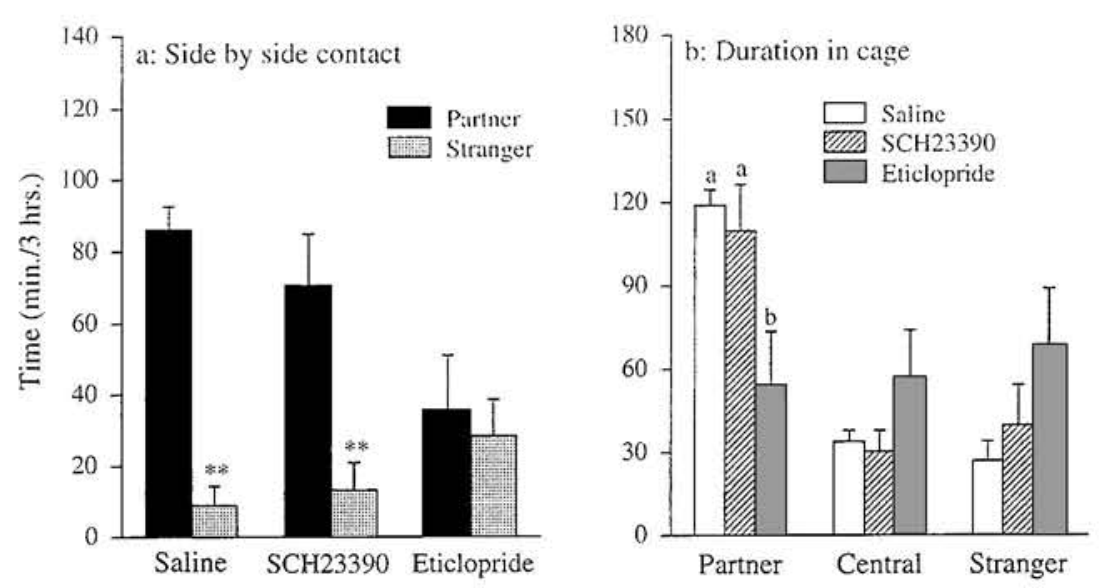

Figure 2. Effects of the dopamine D1 receptor antagonist SCH23390 or D2 receptor antagonist eticlopride on 24-hr, mating-induced partner preferences in female prairie voles. (a) Females injected with either saline or the D1 receptor antagonist before a 24-hr mating session had more side-by-side contact with the partner than with a stranger. (b) These females also spent more time in the partner's cage than did females injected with the D2 receptor antagonist. The latter females had similar contact with either male. ${ }^{* *} p<.01$, Mann-Whitney nonparametric test. The letters illustrate group differences based on a post hoc test following a Kruskal-Wallis nonparametric test. Error bars indicate standard errors of the means.

side-by-side contact with the partner than with a stranger $(Z=3.36, p<.001$; see Figure 3). A partner preference was not observed in females injected with the D1 receptor agonist SKF38393. A similar difference was also found in the time that females spent in each cage (data not shown). The two groups, however, did not differ in locomotor activity during the preference test or in social contact with the male during the $6 \mathrm{hr}$ of cohabitation.

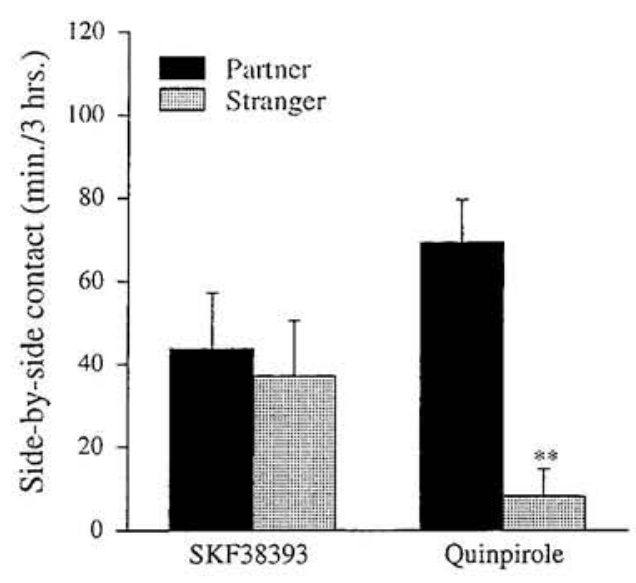

Figure 3. The dopamine agonist induced partner preferences in the absence of mating in female prairie voles. Females injected with the D2 receptor agonist quinpirole before a 6-hr cohabitation with a male had more side-by-side contact with the partner than with a stranger. No such difference was found when females were injected with the D1 receptor agonist SKF38393. For control females injected with saline, see Figure $1 \mathrm{a} .{ }^{*} * p<.01$, MannWhitney nonparametric test. Error bars indicate standard errors of the means.

\section{D2 Receptor Antagonism Affected the Maintenance of Partner Preferences}

Although the above results suggest that the D2 receptor antagonist blocked the formation of a partner preference without inhibiting mating, it is not clear whether the D2 antagonist affected some other aspects of the mating experience that might have precluded the female from developing a conditioned association to her mate. To investigate whether eticlopride's blockade of partner preference was due to effects on mating, we compared females injected with eticlopride immediately after mating with females injected with eticlopride before mating, as in Experiment $2 \mathrm{~A}$. Neither group of females showed a partner preference (see Figure 4a), although, as expected, control females injected with saline had more contact with the partner than with a stranger $(Z=3.13, p<.01)$. Saline-injected females also spent more time in the partner's cage $(H=12.80, p<.01)$ but less time in a stranger's cage $(H=12.04, p<.01)$ compared with females injected with eticlopride (Figure $4 \mathrm{~b}$ ). No treatment differences were detected in locomotor activity during the preference test or in sociosexual behaviors during the first 6 $\mathrm{hr}$ of mating.

\section{D2 Antagonist Did Not Block Partner Preferences After Memory Consolidation}

The blockade of partner preferences by the $\mathrm{D} 2$ antagonist after mating may have been due to dopamine's effects on memory consolidation, sensory recognition, or both. To distinguish between these two mechanisms, females were injected with eticlopride $(50 \mu \mathrm{g}) 24 \mathrm{hr}$ after mating, immediately before being given a partner preference test. Females treated with either eticlopride $(Z=2.31, p<.05)$ or saline 

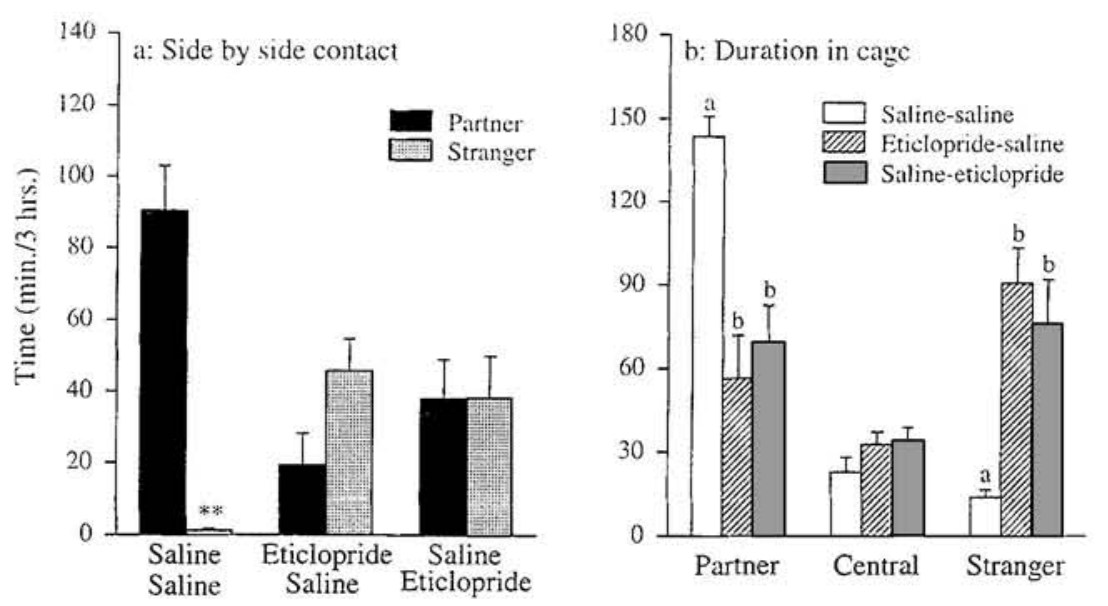

Figure 4. Dopamine D2 receptor antagonist blocked the formation and maintenance of matinginduced partner preferences in female prairie voles. (a) After $24 \mathrm{hr}$ of mating, control females (injected with saline) spent more time with the partner than with a stranger. However, injections of the dopamine D2 receptor antagonist eticlopride before or immediately after mating impaired this behavioral preferences. (b) Females injected with the D2 receptor antagonist also spent less time in the partner's cage but more time in a stranger's cage in comparison with control females. ${ }^{* *} p<.01$, Mann-Whitney nonparametric test. The letters illustrate group differences based on a post hoc test following Kruskal-Wallis nonparametric test. Error bars indicate standard errors of the means.

$(Z=2.21, p<.05) 24 \mathrm{hr}$ after mating displayed a partner preference (see Figure 5a). In addition, both females spent more time in the partner's cage relative to the other two cages $(H=9.38, p<.01$, for the $\mathrm{D} 2$ antagonist group and $H=7.61, p<.05$, for the saline group; see Figure $5 \mathrm{~b}$ ). No treatment effects were detected in either measure, suggesting that eticlopride could not block partner preferences if injected $24 \mathrm{hr}$ after mating and that females injected with eticlopride could distinguish the partner from a stranger.

\section{Dopamine Acts in the CNS to Regulate Partner Preferences}

As expected, females injected intracerebroventricularly with CSF displayed mating-induced partner preferences, as they had more body contact with the partner than with a stranger $(Z=3.07, p<.01)$ and spent more time in the partner's cage relative to the other two cages $(H=14.5$, $p<.01$; see Figure 6). However, females injected with the
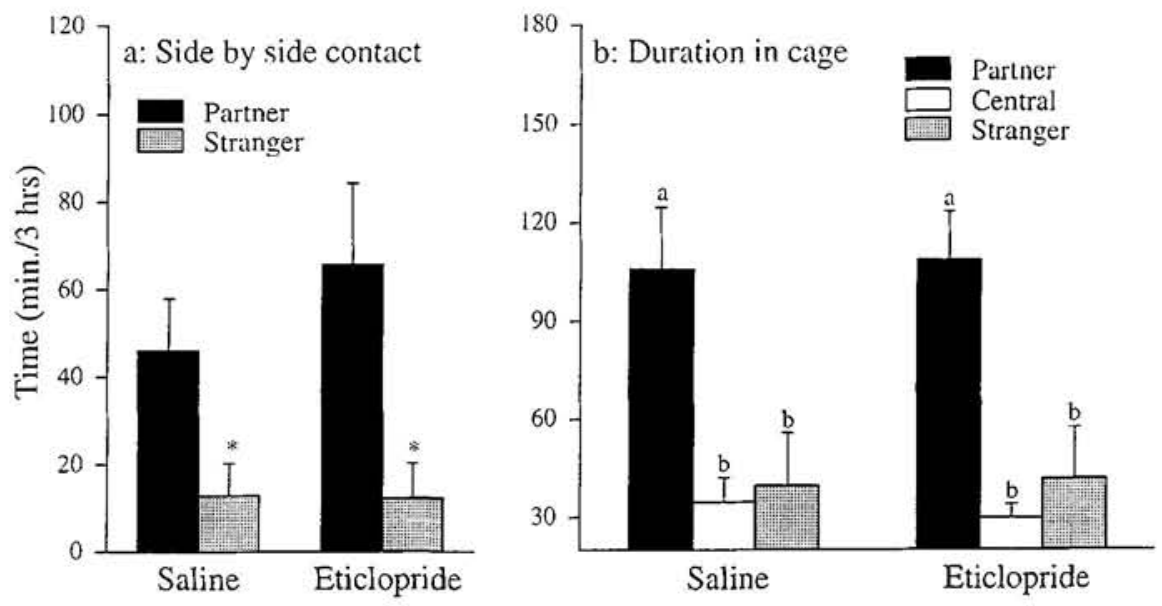

Figure 5. Twenty-four hours after mating, treatment of the $\mathrm{D} 2$ antagonist eticlopride did not influence partner preferences in female prairie voles. (a) Females treated with either saline or eticlopride had more side-by-side contact with the partner than with a stranger. (b) In addition, both females spent more time in the partner's cage than in other cages. ${ }^{*} p<.05$, Mann-Whitney nonparametric test. The letters illustrate group differences based on a post hoc test following Kruskal-Wallis nonparametric test. Error bars indicate standard errors of the means. 

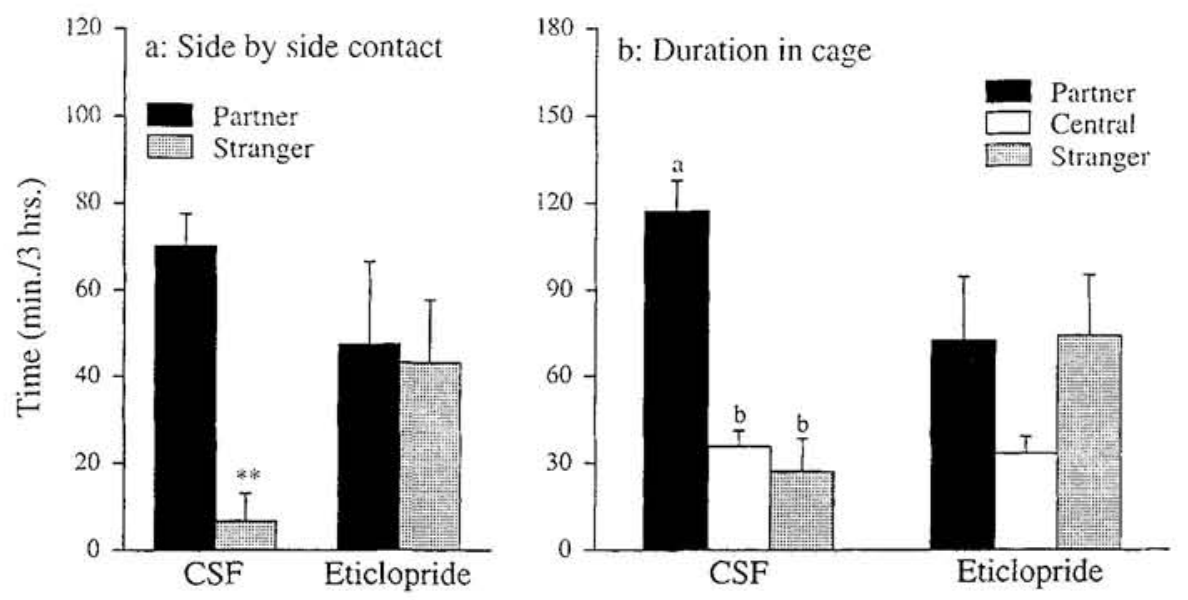

Figure 6. Administration of the D2 antagonist eticlopride into the brain blocked mating-induced partner preferences. (a) Females injected intracerebroventricularly with artificial cerebrospinal fluid (CSF) had more contact with the partner than with a stranger and (b) spent more time in the partner's cage than in other cages. Such behavioral preferences were not found in females injected with eticlopride. ${ }^{* *} p<.01$, Mann-Whitney nonparametric test. The letters illustrate group differences based on a post hoc test following Kruskal-Wallis nonparametric test. Error bars indicate standard errors of the means.

D2 antagonist eticlopride did not show partner preferences, indicating that administration of the D2 antagonist into the brain blocked mating-induced partner preferences.

\section{Discussion}

The prairie vole, a monogamous species in which mating induces pair bonding (Carter \& Getz, 1993; Insel et al., 1995; Shapiro \& Dewsbury, 1990), was studied to determine whether dopamine influences partner preference formation. Results from the present study demonstrate that dopamine acting via a D2 receptor is involved in the formation of partner preferences in female prairie voles. To our knowledge, this is the first study demonstrating a role for dopamine in social attachment in adult animals.

It is important to note that neither the dopamine antagonists nor the agonists (except for a single dose of apomorphine) altered females' behavior toward the male during the initial cohabitation period. In addition, none of the drugs affected locomotor activity during the preference test. These data suggest that the treatment effects on partner preferences were not artifacts of hyper- or hypoactivity, nor were they simply the residual effects of mating or social contact. AIthough there are previous results in rats demonstrating that female sexual receptivity can either be facilitated (Hamburgerbar \& Rigter, 1975) or inhibited (Grierson, James, Person, \& Wilson, 1988) by dopaminergic agents, our observation that administration of the D2 antagonist did not affect mating and that such treatment immediately after mating blocked the partner preference indicates that, in the female prairie vole, eticlopride's inhibition of partner preference formation cannot be due to an influence on sexual behavior.

On the other hand, our data are consistent with the possibility that mating is associated with activation of dopaminergic pathways, as the D2 agonist appeared to facilitate partner preference, mimicking the effects of mating. The notion that mating induces dopamine release is supported by extensive evidence that sexual activity increases dopamine release in rodents. In female rats, for example, the dopamine concentration in the nucleus accumbens, dorsal striatum, and ventromedial hypothalamus, measured by in vivo microdialysis, is significantly increased during sexual activity (Pfaus et al., 1995; Vathy \& Etgen, 1989). In female Syrian hamsters, mating induces a rapid elevation of dopamine release in the ventral striatum, and this dopamine level remains significantly above baseline during the entire period of exposure to a male (Meisel et al., 1993). It has been found that even the sensory stimuli from a male without mating is enough to induce dopamine release, as the dopamine concentration in the nucleus accumbens is increased when female rats are exposed to a male that is separated from them by a wire-mesh screen (Pfaus et al., 1995). In our recent microdialysis study in prairie voles, a $50 \%$ increase in extracellular dopamine concentration was found in the nucleus accumbens in females within $15 \mathrm{~min}$ of mating (Gingrich, Cascio, Liu, Insel, \& Wang, 1998). However, this increase was not found in females that were exposed to a male without mating, suggesting that mating may be essential to induce dopamine release for the regulation of partner preference.

What is the mechanism underlying dopamine's effects on partner preferences? Dopamine has been suggested to play an important role in the reward properties of diverse stimuli including drugs of abuse, appetitive behaviors, and sex (see review by Bozarth, 1991; Damsma, Pfaus, Wenkstern, \& Phillips, 1992; Everitt, Cador, \& Robbins, 1989; Wise \& Rompre, 1989). Everitt and others have previously demonstrated that sex serves as a potent reinforcer in rats. Not only do male rats work to engage in copulation (Sheffield, Wulff, 
\& Backer, 1955) or to gain access to a second-order stimulus associated with copulation (Everitt et al., 1989), but male and female rats also display mating-induced place preferences (Everitt, 1990; Oldenburger, Everitt, \& de Jonge, 1992). Dopamine is released during mating (Mermelstein \& Becker, 1995; Pfaus et al.. 1995; Vathy \& Etgen, 1989). Extrapolating from previous studies with rats, it seems possible that in female voles, copulation is a potent reinforcer. With repeated mating, an association forms between the rewarding or hedonic attributes of mating and the male partner, and dopamine released during repeated copulation may subserve this association at a neurochemical level. Thereafter, the male (or some sensory attribute of the male) is a conditioned stimulus that we have measured as a partner preference. The dopamine receptor blockade administered before mating might disrupt the associative process and decrease the rewarding value of copulation. Previous studies in rats have shown that the D2 receptors are involved in dopamine blockade of reward or reinforcement (Gallistel \& Davis, 1983; Wise \& Rompre, 1989).

In the present study, injections of the D2 receptor antagonist after mating also impaired the partner preference, suggesting that in this case the blockade's effect was not on the formation of the association but on its consolidation or expression. There are many mechanisms by which eticlopride given after mating might block partner preference: inhibition of memory consolidation, impairment of sensory recognition, decreased neophobia, or simply sedation. The latter two possibilities can be ruled out because locomotor activity was not impaired and because we have previously demonstrated that neophobia is not a factor in partner preference formation (Insel et al., 1995). Olfaction plays an important role in the development of partner preferences in prairie voles (Williams, Slotnick, Kirkpatrick, \& Carter, 1992). In rats, odor discrimination is impaired by a D2 receptor antagonist (Wilson \& Sullivan, 1995), and treatment with a D2 receptor agonist increases the threshold of odor detection (Doty \& Risser, 1989). Therefore, it is possible that injections of the D2 antagonist after mating impaired the female's ability to distinguish the familiar partner from a stranger, and thus females spent equal amounts of time in contact with each male. This possibility can be eliminated by our fourth experiment, in which the D2 antagonist did not block partner preferences when subjects were treated $24 \mathrm{hr}$ after mating but immediately before the partner preference test. Therefore, the most likely explanation is that eticlopride given after mating blocked consolidation of the social memory.

In our study, not only did the D2 antagonism block mating-induced partner preferences, but treatment of the D2 agonist induced this behavior in a pattern similar to that produced by mating. This effect of the D2 agonist could not be attributed to the effects on initial social interaction because no group differences were detected. One possibility is that the D2 agonist facilitated the memory formation for a partner by hastening the processes important for individual recognition, as previously reported for vasopressin and oxytocin effects in rats (Dantzer, Bluthe, Koob, \& Le Moal, 1987; Dantzer, Koob, Bluthe, \& Le Moal, 1988; Popik,
Vetulani, \& van Ree, 1992; Renelli et al., 1995). This hypothesis is supported by the observation that the D2 agonist enhances odor detection (Doty \& Risser, 1989) and that the nucleus accumbens, an area enriched with dopamine receptors, is implicated in social memory in rats (Ploeger, Willemen, \& Cools, 1991). Another possibility is that the agonist also acted on the formation and retention of an association, as suggested earlier for the endogenous dopamine effects. The prairie vole is a social animal (Carter \& Getz, 1993). Cohabitation with an opposite-sex individual, even in the absence of mating, might have generated some positive values not only because it provides a social environment but also because it induces a series of physiological and hormonal changes that eventually lead to estrus induction in female voles (Carter, Getz, Gavish, McDermott, \& Amold, 1980; Carter, Witt, Schneider, Harris, \& Volkening, 1987). The D2 agonist might act to facilitate an association between the male partner and this social reward. Surprisingly, in a preliminary study, apomorphine did not induce partner preferences in female montane voles, at least at the same dose that induced partner preferences in female prairie voles (Wang, Cascio, \& Inse1, 1998), indicating that dopamine's effects on partner preferences formation are specifically associated with monogamous pair bonding in voles.

Our data suggest that dopamine is involved in the regulation of partner preferences by acting on a $D 2$ receptormediated mechanism. Although the D1 receptor agonist and antagonist did not influence partner preferences in the present study, the possibility that D1 receptors are involved in the regulation of this behavior cannot be completely ruled out. Dopamine's effects on behaviors are dose dependent (e.g., sexual behavior; Melis \& Argiolas, 1995). It is possible that a higher or lower dose of the D1 receptor agonist or antagonist might have effects on partner preferences.

If mating induces dopamine release and if released dopamine acts on reward-memory pathways to induce a partner preference, then why do promiscuous species such as rats, hamsters, or montane voles fail to pair bond after mating (Insel et al., 1995; Shapiro \& Dewsbury, 1990)? Several possibilities exist. First, mating may induce dopamine release in a species-specific manner. In previous studies, mating induced central vasopressin release in monogamous male prairie voles but not in promiscuous male voles, suggesting that mating may have different neural consequences in monogamous and nonmonogamous voles (Bamshad, Novak, \& De Vries, 1994; Wang, Smith, Major, \& De Vries, 1994). Second, species may differ in their behavioral responsiveness to released dopamine, especially if they differ in dopamine receptor distribution or affinity. For instance, prairie and montane voles differ in the regional expression of oxytocin and vasopressin receptors in the brain and in their functional responses to these peptides (Insel \& Shapiro, 1992; Insel, Wang, \& Ferris, 1994). A third possibility is that if dopamine interacts with other neurotransmitter systems to regulate partner preferences, species differences in the second neurotransmitter that is positioned either before or after the dopaminergic neuron may account for differences in behavior. It is known, for instance, that 
dopamine and oxytocin interact to regulate penile erection, yawning, and grooming in rats (Argiolas, Melis, \& Gessa, 1988; Drago et al., 1986; Melis, Argiolas, \& Gessa, 1989; Stivers, Kaltwasser, Hill, Hruby, \& Crawley, 1988) and that oxytocin is also involved in the regulation of partner preferences in female prairie voles (Insel \& Hulihan, 1995; Williams et al., 1994). Finally, relative to rats and mice, prairie voles exhibit a much higher number of copulations over a $24-\mathrm{hr}$ period. Although prairie voles and montane voles are similar in mating frequency (Insel \& Hulihan, 1995), they differ in specific components of sexual behavior. Prairie voles display a slower rate of intravaginal thrusting and need fewer ejaculations to reach satiety than do montane voles (Dewsbury, 1973; Dewsbury, 1975; Gray \& Dewsbury, 1973). The vaginal sensory mechanism plays an important role in reward (Oldenburger et al., 1992). Speciesspecific patterns of sexual behavior may impact the subsequent processing of motivated behaviors. These scenarios, as well as the action sites of dopamine and the interaction of dopamine with other neurotransmitter systems in the regulation of partner preferences, are under investigation in our current studies.

\section{References}

Argiolas, A., Melis, M. R., \& Gessa, G. L. (1988). Yawning and penile erection: Central dopamine-oxytocin-adrenorticotropin connection. In D. L. Colbern \& W. H. Gispen (Eds.), Annals of the New York Academy of Sciences: Vol. 525. Neural mechanisms and biological significance of grooming behavior (pp. 330-337). New York: New York Academy of Sciences.

Bamshad, M., Novak, M. A., \& De Vries, G. J. (1994). Cohabitation alters vasopressin innervation and paternal behavior in prairie voles (Microtus ochrogaster). Physiology \& Behavior, $56,751-758$.

Blackburn, J. R., Pfaus, J. G., \& Phillips, A. G. (1992). Dopamine functions in appetitive and defensive behaviours. Progress in Neurobiology, 39, 247-279.

Bozarth, M. A. (1991). The mesolimbic dopamine system as a model reward system. In P. Willner \& J. Scheel-Kruger (Eds.), The mesolimbic dopamine system: From motivation to action (pp. 301-330). New York: Wiley.

Carter, C. S., \& Getz, L. L. (1993). Monagamy and the prairie vole. Scientific American, 268, 100-106.

Carter, C. S., Getz, L. L., Gavish, L., McDermott, J. L., \& Arnold, P. (1980). Male-related pheromones and the activation of female reproduction in the prairie vole (Microtus ochrogaster). Biology of Reproduction, 23, 1038-1045.

Carter, C. S., Witt, D. M., Schneider, J., Harris, Z. L., \& Volkening, D. (1987). Male stimuli are necessary for female sexual behavior and uterine growth in prairie voles (Microtus ochrogaster). Hormones and Behavior, 21, 74-82.

Castellano, C., Cestari, V., Cabib, S., \& Puglisi-Allegra, S. (1991). Post-training dopamine receptor agonists and antagonists affect memory storage in mice irrespective of their selectivity for D1 or D2 receptors. Behavioral and Neural Biology, 56, 283-291.

Castellano, C., Cestari, V., Cabib, S., \& Puglisi-Allegra, S. (1994). The effects of morphine on memory consolidation in mice involve both $\mathrm{D} 1$ and $\mathrm{D} 2$ dopamine receptors. Behavioral and Neural Biology, 61, 156-161.

Damsma, G., Pfaus, J. G., Wenkstern, D., \& Phillips, A. G. (1992). Sexual behavior increases dopamine transmission in the nucleus accumbens and striatum of male rats: Comparison with novelty and locomotion. Behavioral Neuroscience, 106, 181-191.

Dantzer, R., Bluthe, R. -M., Koob, G. F., \& Le Moal, M. (1987). Modulation of social memory in male rats by neurohypophyseal peptides. Psychopharmacology, 91, 363-368.

Dantzer, R., Koob, G. F., Bluthe, R. M., \& Le Moal, M. (1988). Septal vasopressin modulates social memory in male rats. Brain Research, 457, 143-147.

Dewsbury, D. A. (1973). Copulatory behavior of montane voles (Microtus montanus). Behaviour, 44, 186-201.

Dewsbury, D. A. (1975, December). Diversity and adaptation in rodent copulatory behavior. Science, 190, 947-954.

Dewsbury, D. A. (1987). The comparative psychology of monogamy. Nebraska Symposium on Motivation, 35, 1-50.

Doty, R. L., \& Risser, J. M. (1989). Influence of the D2 dopamine receptor agonist quinpirole on the odor detection performance of rats before and after spiperone injection. Psychopharmacology, 98, 310-315.

Drago, F., Caldwell, J. D., Pedersen, C. A., Continella, G., Scapagnini, U., \& Prange, A. J. (1986). Dopamine neurotransmission in the nucleus accumbens may be involved in oxytocinenhanced grooming behavior of the rat. Pharmacology, Biochemistry \& Behavior, 24, 1185-1188.

Everitt, B. J. (1990). Sexual motivation: A neural and behavioral analysis of the mechanisms underlying appetitive and copulatory responses of male rats. Neuroscience and Biobehavioral Review, 14, 217-232.

Everitt, B. J., Cador, M., \& Robbins, T. W. (1989). Interactions between the amygdala and ventral striatum in stimulus-reward associations: Studies using a second-order schedule of sexual reinforcement. Neuroscience, 30, 63-75.

Gallistel, C. R., \& Davis, A. J. (1983). Affinity for the dopamine D2 receptor predicts neuroleptic potency in blocking the reinforcing effect of MFB stimulation. Pharmacology, Biochemistry \& Behavior, 19, 867-872.

Getz, L. L., Carter, S. C., \& Gavish, L. (1981). The mating system of the prairie vole, Microtus ochrogaster: Field and laboratory evidence for pair-bonding. Behavioral Ecology and Sociobiology, 8, 189-194.

Getz, L. L., \& Hofmann, J. E. (1986). Social organizations in free-living prairie voles, Microtus ochrogaster. Behavioral Ecology and Sociobiology, 18, 275-282.

Gingrich, B. S., Cascio, C., Liu, Y., Insel, T. R., \& Wang, Z. X. (1998). Role of the nucleus accumbens in dopamine regulation of partner preferences in female prairie voles. Society for Behavioral Neuroendocrinology Abstracts, 53.

Gray, G., \& Dewsbury, D. (1973). A quantitative description of copulatory behavior in prairie voles (Microtus ochrogaster). Brain, Behavior \& Evolution, 8, 437-452.

Grierson, J. P., James, M. D., Person, J. R., \& Wilson, C. A. (1988). The effect of selective D1 and D2 dopaminergic agents on sexual receptivity in the female rat. Neuropharmacology, 27, 181-189.

Hamburger-bar, R., \& Rigter, H. (1975). Apomorphine: Facilitation of sexual behaviour in female rats. European Journal of Pharmacology, 32, 357-360.

Insel, T. R., \& Hulihan, T. J. (1995). A gender-specific mechanism for pair bonding: Oxytocin and partner preference formation in monogamous voles. Behavioral Neuroscience, 109, 782-789.

Insel, T. R., Preston, S., \& Winslow, J. T. (1995). Mating in the monogamous male: Behavioral consequences. Physiology \& Behavior, 57, 615-627.

Insel, T. R., \& Shapiro, L. E. (1992). Oxytocin receptor distribution reflects social organization in monogamous and polygamous voles. Proceedings of the National Academy of Sciences, USA, $89,5981-5985$. 
Insel, T. R., Wang, Z. X., \& Ferris, C. F. (1994). Patterns of brain vasopressin receptor distribution associated with social organization in microtine rodents. Journal of Neuroscience, 14. 53815392.

McGuire, B., \& Novak, M. A. (1984). A comparison of maternal behaviour in the meadow voles (Microtus pennsylvanicus), prairie voles (M. ochrogaster) and pine vole (M. pinetorum). Animal Behaviour, 32, 1132-1141.

Meisel, R. L., Camp, D. M., \& Robinson, T. E. (1993). A microdialysis study of ventral striatal dopamine during sexual behavior in female Syrian hamsters. Behavioural Brain Research, 55, 151-157.

Melis, M. R., \& Argiolas, A. (1995). Dopamine and sexual behavior. Neuroscience and Biobehavioral Review, 19, 19-38.

Melis, M. R., Argiolas, A., \& Gessa, G. L. (1989). Evidence that apomorphine induces penile erection and yawning by releasing oxytocin in the central nervous system. European Journal of Pharmacology, 164, 565-570.

Mermelstein, P. G., \& Becker, J. B. (1995). Increased extracellular dopamine in the nucleus accumbens and striatum of the female rat during paced copulatory behavior. Behavioral Neuroscience, 109, 354-365.

Oldenburger, W. P., Everitt, B. J., \& de Jonge, F. H. (1992). Conditioned place preference induced by sexual interaction in female rats. Hormones and Behavior, 26, 214-228.

Oliveras, D., \& Novak, M. (1986). A comparison of paternal behaviour in the meadow vole Microtus pennsylvanicus, the pine vole $M$. pinetorum and the prairie vole $M$. ochrogaster. Animal Behaviour, 34, 519-526.

Pfaus, J. G., Damsma, G., Wenkstern, D., \& Fibiger, H. C. (1995). Sexual activity increases dopamine transmission in the nucleus accumbens and striatum of female rats. Brain Research, 693, 21-30.

Ploeger, G. E., Willemen, A. P. M., \& Cools, A. R. (1991). Role of the nucleus accumbens in social memory in rats. Brain Research Bulletin, 26, 23-27.

Popik, P., Vetulani, J., \& van Ree, J. M. (1992). Low doses of oxytocin facilitate social recognition in rats. Psychopharmacology, 106, 71-74.

Renelli, A., Bertolini, A., Poggioli, R., Menozzi, B., Basaglia, R., \& Arletti, R. (1995). Polymodal dose-response curve for oxytocin in the social recognition test. Neuropeptides, 28, 251-255.

Shapiro, L. E., \& Dewsbury, D. A. (1990). Differences in affiliative behavior, pair bonding, and vaginal cytology in two species of voles (Microtus ochrogaster and $M$. montanus). Journal of Comparative Psychology, 104, 268-274.

Sheffield, F. D., Wulff, J. J., \& Backer, R. (1955). Reward value of copulation without sex drive reduction. Journal of Comparative Physiological Psychology, 44, 3-8.
Stivers, J. A., Kaltwasser, M. T., Hill, P. S., Hruby, V. J., \& Crawley, J. N. (1988). Ventral tegmental oxytocin induces grooming. Peptides, 9 (Suppl. 1), 223-231.

Vathy, I., \& Etgen, A. M. (1989). Hormonal activation of female sexual behavior is accompanied by hypothalamic norepinephrine release. Journal of Neuroendocrinology, 1, 383-388.

Wang, Z. X., Cascio, C., \& Insel, T. R. (1998). Effects of brain dopamine on partner preference in prairie voles and montane voles. Unpublished manuscript.

Wang, Z. X., Ferris, C. F., \& De Vries, G. J. (1994). Role of septal vasopressin innervation in paternal behavior in prairie voles (Microtus ochrogaster). Proceedings of the National Academy of Sciences, USA, 91, 400-404.

Wang, Z. X., Smith, W., Major, D. E., \& De Vries, G. J. (1994). Sex and species differences in the effects of cohabitation on vasopressin messenger RNA expression in the bed nucleus of the stria terminalis in prairie voles (Microtus ochrogaster) and meadow voles (Microtus pennsylvanicus). Brain Research, 650, 212-218.

Williams, J. R., Catania, K. C., \& Carter, C. S. (1992). Development of partner preferences in female prairie voles (Microtus ochrogaster): The role of social and sexual experience. Hormones and Behavior, 26, 339-349.

Williams, J. R., Insel, T. R., Harbaugh, C. R., \& Carter, C. S. (1994). Oxytocin administered centrally facilitates formation of a partner preference in female prairie voles (Microtus ochrogaster). Journal of Neuroendocrinology, 6, 247-250.

Williams, J. R., Slotnick, B. M., Kirkpatrick, B. W., \& Carter, C. S. (1992). Olfactory bulb removal affects partner preference development and estrus induction in female prairie voles. Physiology \& Behavior, 52, 635-639.

Wilson, D. A., \& Sullivan, R. M. (1995). The D2 antagonist spiperone mimics the effects of olfactory deprivation on mitral/ tufted cell odor response patterns. Journal of Neuroscience, 15 , 5574-5581.

Winslow, J. T., Hastings, N., Carter, C. S., Harbaugh, C. R., \& Insel, T. R. (1993, October). A role for central vasopressin in pair bonding in monogamous prairie voles. Nature, 365, 545-548.

Wise, R. A., \& Rompre, P. P. (1989). Brain dopamine and reward. Annual Review of Psychology, 40, 191-225.

Young, L. J., Wang, Z. X., \& Insel, T. R. (1997). Neuroendocrine bases of monogamy. Trends in Neuroscience, 21, 71-75.

Received July 21, 1998

Revision received November 25, 1998 Accepted November 30, 1998 